\title{
ARTIGO
}

DOI: https://doi.org/10.22481/praxis.v14i29.4116

\section{CULTURA VISUAL NA FORMAÇÃO DOCENTE EM ARTES VISUAIS: UM OLHAR SOBRE A PRODUÇÃO CIENTÍFICA}

\author{
VISUAL CULTURE IN TEACHING TRAINING IN VISUAL ARTS: A LOOK AT \\ SCIENTIFIC PRODUCTION
}

\author{
CULTURA VISUAL EN LA FORMACIÓN DOCENTE EN ARTES VISUALES: UNA \\ MIRADA SOBRE LA PRODUCCIÓN CIENTÍFICA
}

\author{
Maristani Polidori Zamperetti \\ Universidade Federal de Pelotas - Brasil \\ Fabiana Lopes de Souza \\ Universidade Federal de Pelotas - Brasil
}

\begin{abstract}
Resumo: O presente estudo é parte de uma pesquisa em andamento, advinda dos questionamentos acerca da docência e das vivências profissionais e pessoais dos professores de Artes Visuais, em relação às visualidades contemporâneas. Os meios de comunicação de massa e o universo visual invadem nossas vivências cotidianas, influenciando-nos e definindo/desconstruindo identidades, num processo de transitoriedade e fluidez. Conforme aponta Martins (2005), a cultura visual é um campo novo de investigação proveniente dos Estudos Culturais que tem foco no visual e na experiência cotidiana, e abrange "[...] espaços e maneiras como a cultura se torna visível e o visível se torna cultura. Corpus de conhecimento emergente [...]". Este recorte visa discutir as produções científicas que entrelaçam as temáticas da cultura visual e da formação docente em Artes Visuais. A partir do levantamento documental em bases de busca com as palavras-chave: Cultura Visual, Ensino de Artes Visuais e Formação de Professores buscou-se conhecer as produções científicas da área e os entendimentos acerca da cultura visual no ensino e formação de professores. O trabalho é de cunho quali-quantitativo, buscando compreender a relevância e a quantidade de produções divulgadas. $\mathrm{O}$ método utilizado conta com a coleta de dados, efetuado em plataforma virtual, em meios de divulgação científica das universidades e redes acadêmicas.
\end{abstract}

Palavras-chave: Cultura visual. Formação de professores. Produção científica.

\begin{abstract}
The present study is part of a research in progress, arising from questions about teaching and the professional and personal experiences of teachers of Visual Arts, in relation to contemporary visuals. The mass media and the visual universe invade our everyday experiences, influencing us and defining / deconstructing identities, in a process of transience and fluidity. As Martins (2005) points out, visual culture is a new field of research from Cultural Studies that focuses on visual and everyday experience, and encompasses "[...] spaces and ways in which culture becomes visible and visible Becomes culture. Corpus of emerging knowledge [...] ". This section aims to discuss the scientific productions that interweave the themes of visual culture and teacher training in Visual Arts. From the documentary search in search bases with the keywords: Visual Culture, Teaching of Visual Arts and Teacher Training, we sought to know the scientific productions of the area and the understandings about the visual culture in the teaching and training of teachers. The work is qualitative-quantitative, seeking to understand the relevance and quantity of productions disclosed. The method used relies on
\end{abstract}


the collection of data, carried out on a virtual platform, in means of scientific dissemination of the universities and academic networks.

Keywords: Visual Culture. Teacher formation. Scientific production.

Resumen: El presente estudio forma parte de una investigación en curso, que viene de los cuestionamientos acerca de la docencia y de las vivencias profesionales y personales de los profesores de Artes Visuales, en relación a las visualidades contemporáneas. Los medios de comunicación masiva y el universo visual invaden nuestras vivencias cotidianas, influenciándonos y definiendo / desconstruyendo identidades, en un proceso de transitoriedad y fluidez. La cultura visual es un campo nuevo de investigación proveniente de los Estudios Culturales que tiene foco en el visual y la experiencia cotidiana, y abarca "[...] espacios y maneras como la cultura se torna visible y lo visible se convierte en cultura. Corpus de conocimiento emergente [...]. Este recorte pretende discutir las producciones científicas que entrelazan las temáticas de la cultura visual y de la formación docente en Artes Visuales. A partir del levantamiento documental en bases de búsqueda con las palabras clave: Cultura Visual, Enseñanza de Artes Visuales y Formación de Profesores se buscó conocer las producciones científicas del área y los entendimientos acerca de la cultura visual en la enseñanza y formación de profesores. El trabajo es de cuño cuantitativo, buscando comprender la relevancia y la cantidad de producciones divulgadas. El método utilizado cuenta con la recolección de datos, efectuado en plataforma virtual, en medios de divulgación científica de las universidades y redes académicas.

Palabras clave: Cultura visual. Formación de profesores. Producción científica.

\section{Introdução}

O projeto de pesquisa vinculado ao Centro de Artes/UFPel e ao PPGE/FaE/UFPel, intitulado "Cultura Visual no Ensino de Artes Visuais - sentidos, práticas e experiências docentes" (2016), adveio dos questionamentos acerca da docência em Artes Visuais e as vivências profissionais e pessoais dos professores dessa área de conhecimento, em relação às visualidades contemporâneas. Buscamos entender, por meio de pesquisas, quais visualidades estão presentes nas práticas pedagógicas desenvolvidas pelos professores de Artes Visuais e que relações estabelecem entre as suas experiências pessoais e a cultura visual contemporânea. Pretendemos possibilitar a reflexão acerca da utilização de imagens em sala de aula pelos futuros docentes ou docentes atuantes na rede de ensino pelotense, identificando as relações que os professores de Artes Visuais estabelecem entre a cultura visual, seu ensino, sua profissão docente e vida pessoal.

Assim, o presente artigo é um recorte desta pesquisa em andamento, que realiza no momento, um levantamento bibliográfico em bases de dados de publicações científicas como a SciELO (Scientific Electronic Library Online), os anais das reuniões científicas nacionais da ANPED, os anais do Seminário Nacional de Pesquisa em Arte e Cultura Visual, nos artigos 
da Revista Visualidades (UFG) e no banco de teses e dissertações do Programa de Pósgraduação em Arte e Cultura Visual da Universidade Federal de Goiás (UFG). Neste artigo abordaremos a busca realizada em apenas duas bases pesquisadas - na SciELO e na ANPED, ressaltando que a pesquisa se encontra ainda em estado inicial. A pesquisa é de base bibliográfica e por meio das palavras-chave - Cultura Visual, Ensino de Artes Visuais e Formação de Professores -, tem como objetivo conhecer as produções científicas da área e os entendimentos acerca da cultura visual no ensino e formação de professores. O trabalho é de cunho quali-quantitativo, buscando compreender a relevância e a quantidade de produções divulgadas.

\section{Formação docente: processos de aprendizagem em construção}

Processo de cunho contínuo e dinâmico, que dura toda a vida, a formação docente coloca em evidência a legitimação do saber profissional e pessoal produzido pelos professores em seus contextos cotidianos de trabalho. Podemos, desta forma, pensar a formação docente como uma formação humana, que tem variações e apresenta dificuldades e/ou avanços, com tempos variados, de acordo com os sujeitos em formação. Confunde-se, por vezes, com a própria vida e as vivências cotidianas dos sujeitos, embora as múltiplas variações dos tempos cronológicos não coincidam com o transcurso dos dias letivos escolares, fazendo com que estejamos sempre no vir-a-ser, no vir-a-se-tornar alguém. (ASSMANN, 2004; TARDIF, 2002).

Os saberes produzidos pelos professores (na sua prática e na sua vida em geral) têm motivado estudos na área da formação docente, especialmente nas duas últimas décadas. As indagações sobre a formação, os saberes e a aprendizagem profissional da docência são temas relevantes de pesquisa e têm repercutido nas práticas docentes. Inseridos nessa temática estão os estudos sobre a subjetividade do docente e as circunstâncias envolvidas na sua formação.

Neste processo subjetivo de vivências temporais, com variações múltiplas, ocorrem as formações endereçadas ao próprio sujeito (autoformativas), que são, por vezes, difíceis de serem reconhecidas, pois extrapolam os contextos cronológicos de vida e aprendizagem profissional, como aponta Larrosa (2002) ao explicar a formação humana como “[...] um devir plural e criativo, sem padrão e sem projeto, sem uma ideia prescritiva de seu itinerário e sem uma ideia normativa, autoritária e excludente de seu resultado [...]”. (LARROSA, 2002, p.139). 
Diferentes propostas de formação docente são possíveis - autoformação, heteroformação e/ou interformação ${ }^{1}$ - porém, o que se pode afirmar é que a necessidade da aprendizagem ao longo da vida é fator fundamental para o desenvolvimento profissional, ao que Assmann (2004) denomina life-long learning, conceito inevitavelmente elástico, que inclui todo tipo de participação ativa dos sujeitos aprendentes em processos cognitivos. Portanto, não podemos ter um conceito unívoco sobre a formação docente, pois esta é dinâmica e constituída de valores, suposições, quadros referenciais, crenças pessoais e desejos dos aprendentes, ancorada nas experiências que o profissional tem como pessoa e professor.

A aprendizagem por toda a vida é um processo voluntário, no qual o sujeito automotivado busca o conhecimento por razões pessoais ou profissionais. O termo indica que a aprendizagem não está restrita à infância ou à sala de aula, mas ocorre ao longo da vida e em uma escala de diferentes situações, nas interações diárias com os outros e com o mundo que nos cerca. Esse processo confunde-se com a própria vida, uma vez que pressupõe aprendizagem e formação contínua.

A formação docente, inserida no campo de estudo da educação de adultos, permite, segundo Josso (2004), o surgimento de investigações sobre os temas da formação e autoformação, propondo desafios na relação pedagógica que se processa entre adultos. Para a autora, a formação docente envolve a incorporação explícita do saber-fazer e dos conhecimentos em práticas pedagógicas que possibilitam aprendizagens em processo de integração dos níveis psicológico, psicossociológico, sociológico, político, cultural e econômico. Percebendo como esta formação se processa, Josso entende que o professor aprende pela experiência direta, ao observar experiências formadoras que o qualificam como docente, com mais ou menos rigor.

O conceito de formação docente apresenta diferentes perspectivas, de acordo com a interpretação do sujeito e sua subjetividade. Nesse processo acontece uma dependência intrínseca de quem planeja a formação com o que é ofertado como possibilidade experiencial, do que é organizado e é exercitado como proposta formativa, ou é vivido como iniciativa pessoal do sujeito em seu próprio processo. Portanto, a formação

[...] pode ser entendida como uma função social de transmissão de saberes, de saber-fazer ou do saber-ser que se exerce em benefício do sistema

\footnotetext{
${ }^{1}$ Debesse (1992) faz distinções entre autoformação, heteroformação e interformação, esclarecendo que, além dos componentes pessoais de formação, estão nestes conceitos as relações entre os sujeitos aprendentes. Na autoformação o sujeito aprende de forma independente, tendo sob o seu controle os objetivos, os processos, os instrumentos e os resultados da própria formação. Em contrapartida, a heteroformação é organizada e desenvolvida por especialistas (do contexto ou não de trabalho), sem que haja comprometimento do sujeito em formação que dela participa. A interformação é a formação que ocorre entre os próprios professores, em fase de atualização de conhecimentos apoiada pela equipe pedagógica.
} 
socioeconômico, ou da cultura dominante. [Também] pode ser entendida como um processo de desenvolvimento e de estruturação da pessoa que se realiza com o duplo efeito de uma maturação interna e de possibilidades de aprendizagem, de experiências dos sujeitos. (GARCÍA, 1999, p. 19).

Iniciando-se antes do ingresso nos cursos de preparação para o magistério, a formação docente prossegue durante a vida do profissional; além disso, as experiências anteriores dos futuros professores, adquiridas ao longo de sua vida estudantil têm grande influência nesta formação. Porém, a formação inicial é extremamente relevante para a formação profissional, constituindo-se na primeira fase de um longo processo de desenvolvimento profissional. No exercício da profissão, em contato com suas práticas pedagógicas, o professor adquire saberes, evidenciando a ampliação da formação docente para além dos bancos universitários.

García (1999) afirma que a área de formação de professores é complexa e frutífera para o conhecimento e investigação. Para o autor, a pesquisa nessa área resulta em soluções para as questões da formação docente, além de problematizar os sistemas educativos. É uma área que "pode e deve responder a princípios de sistematização, orientação para metas, organização, acompanhamento e controle como qualquer outro processo educativo". (1999, p. 14).

O professor é essencialmente um agente de mudanças, sendo responsável por sua produção de conhecimentos e pelos acontecimentos de seu cotidiano. A percepção dessa situação é preponderante para os estudos sobre formação docente, evidenciando a necessidade de extrapolação da concepção da docência ser uma profissão reprodutora de ideias e transmissora de conhecimentos preestabelecidos por outros sujeitos. O docente, entendido como sujeito autônomo e responsável por suas práticas, encaminha-se cada vez mais para a autoformação e para a pesquisa e reflexão no seu fazer, oxigenando assim o seu ambiente de trabalho.

\section{Cultura visual - sentidos para a educação}

Campo de estudos e investigação, a cultura visual originou-se da área de pesquisa dos Estudos Culturais ${ }^{2}$. De acordo com Nelson et al (2005, p. 13), os Estudos Culturais constituem um “[...] campo interdisciplinar, transdisciplinar e algumas vezes contradisciplinar que atua na tensão entre as tendências para abranger tanto uma concepção ampla,

\footnotetext{
${ }^{2}$ Os Estudos Culturais tiveram seus trabalhos principiados no Centre for Contemporary Cultural Studies (CCCS) em 1964, na Universidade de Birmingham no Reino Unido.
} 
antropológica, de cultura, quanto uma concepção estreitamente humanística de cultura [...]”. Desta forma, os Estudos Culturais atuam na investigação das práticas e produções culturais, e como estas ações contribuem ou determinam concepções de cultura.

A pedagogia foi um dos campos mobilizados pelos Estudos Culturais, e devido a outros fatores sociais, culturais e políticos, teve sua área de estudo ampliada, de forma a trazer novos questionamentos, num processo de complexidade permanente.

Indícios apontam ter sido a partir da aproximação entre Estudos Culturais e Educação que as análises inserindo a pedagogia dentro de uma rede de significações relacionada com cultura, política e poder encontraram embasamento teórico. Foi neste cenário que o conceito de pedagogias culturais surgiu como uma produtiva ferramenta teórica acionada para discutir a relação entre artefatos da cultura e processos educativos. (COSTA; ANDRADE, 2015, p. 49).

Para Giroux (1995), o entendimento de que ocorre pedagogia e processos educativos em todo o lugar em que o conhecimento é produzido, e que os saberes resultantes destas situações, extrapolam os limites impostos pelas instituições, como a escola, por exemplo, nos leva a compreender a cultura como uma área privilegiada de produção de práticas culturais de significação que podem, porventura, educar. De forma semelhante, Giroux e McLaren, sustentam que:

Existe pedagogia em qualquer lugar em que o conhecimento é produzido, em qualquer lugar em que existe a possibilidade de traduzir a experiência e construir verdades, mesmo que essas verdades pareçam irremediavelmente redundantes, superficiais e próximas ao lugar-comum. (1998, p. 144).

A cultura visual, outro campo de estudos derivado dos Estudos Culturais, estabelece relações entre campos diversos, e tem sido pensada principalmente no âmbito da educação em Artes Visuais, embora não se restrinja a esta. A cultura visual é um campo de estudos multidisciplinar que abrange não só as artes, mas também outras áreas de conhecimento como: a sociologia, a psicologia, a antropologia, entre outras.

Os estudos referentes à cultura visual nas artes vão além das visualidades artísticas, procurando investigar também as imagens produzidas pela mídia e todas as provenientes da vida cotidiana. Desta forma, a cultura visual aborda "[...] espaços e maneiras como a cultura se torna visível e o visível se torna cultura. Corpus de conhecimento emergente, [...] a cultura visual é considerada um campo novo em razão do foco no visual com prioridade da experiência no cotidiano. (MARTINS, 2005, p. 135). Assim, os estudos sobre a cultura visual se aproximam das investigações acerca das pedagogias culturais, entendendo que as 
visualidades educam a partir do conhecimento que é produzido, em qualquer lugar que exista a possibilidade de construção de pensamentos e questionamentos sobre o que é apresentado.

As representações visuais que formam a cultura contemporânea determinam padrões, formando o olhar e contribuindo na formação de valores das pessoas. A exposição às visualidades presentes no cotidiano, nas quais o consumo, a aceleração do tempo que se torna cada vez mais exíguo, o acesso ao excesso de informações, passa a "[...] nos definir como integrantes de um mundo conectado, interligado, fugaz, caótico, de mudanças por vezes desconcertantes. Em nosso cotidiano, as imagens decorrentes destas mudanças desempenham um papel que, muitas vezes, nos escapa”. (MEIRA; SILVA, 2013, p. 40).

Estudantes e professores têm acesso diário a um universo de imagens divulgadas em diferentes mídias: televisão, videogames, computadores, smartphones, entre outros. Conforme sustenta Hernández (2000), o estudo da cultura cotidiana promove a possibilidade de aprendizagem e interpretação de múltiplos pontos de vista, favorecendo a conscientização sensível e crítica acerca de si mesmos e do mundo que fazemos parte.

Vieira da Cunha (2007, p. 135) denomina de pedagogia da visualidade o conjunto de imagens dispostos nas instituições escolares, entendendo que as mesmas produzem experiências estéticas “[...] e éticas, modelando a percepção e as relações com o mundo, contribuem na elaboração do imaginário, modelam subjetividades e identidades", especialmente nas crianças. A autora afirma que estas pedagogias visuais formam um currículo paralelo, que funciona no interior das escolas e repercute ao externo social, construindo um tipo de currículo visual, produzindo efeitos de sentido nos componentes deste ambiente.

É possível pensar que as percepções e sentidos atribuídos às imagens e objetos da cultura visual apresentam, na maioria das vezes, distinção entre as qualidades estéticas e as representações sugeridas. Assim, é importante proporcionar a educação do olhar em todos os contextos escolares, na formação inicial e continuada de professores, para que esses possam desenvolver uma educação estética na escola, a partir de suas próprias experiências. Portanto, é fundamental a compreensão da cultura visual quanto aos diferentes tipos de representações visuais de culturas. Objetos consagrados da história da arte do passado fazem parte da cultura visual, assim como os produzidos no presente e também diferentes manifestações visuais contemporâneas, em constante questionamento sobre seu valor artístico.

Conforme assegura Hernández (2000), os artefatos visuais são produtos de um contexto histórico, cultural e social que podem afetar a percepção e a estética. Portanto, diferentes sentidos e significados podem ser atribuídos às vivências e experiências visuais. 
Assim, o trabalho do professor de Artes Visuais é fundamental para uma compreensão crítica dos estudantes em contato com a cultura visual, pois necessita contemplar as experiências dentro e fora da sala de aula.

A multiplicidade das manifestações visuais necessita de variadas estratégias de compreensão, a partir das imagens e artefatos culturais. Assim, a atenção deve ser dada

[...] não só dos objetos considerados canônicos, mas sim dos que se produzem no presente e aqueles que fazem parte do passado; os que se vinculam à própria cultura e com as de outros povos, mas ambas desde a dimensão de "universo simbólico"; os que estão nos museus e os que aparecem nos cartazes publicitários e nos anúncios; nos videoclips ou nas telas da internet; os realizados pelos docentes e pelos próprios alunos. (HERNÁNDEZ, 2000, p.50).

Portanto, as imagens e artefatos visuais a serem estudados nas aulas de Artes Visuais não devem ser limitados a critérios de gosto, mas sim a propostas de compreensão destas representações. Desta forma caberia pensar se as imagens utilizadas pelos professores são escolhidas a partir de gostos pessoais, sugeridas pelos diversos meios de comunicação de massa ou outros fatores, e se as mesmas produzem sentido para os mesmos, reverberando numa educação estética.

A educação estética contribui para uma melhor compreensão do mundo onde professores e alunos estão inseridos. Neste contexto podem ser desenvolvidas experiências sensíveis permeadas pelas relações estabelecidas com a cultura visual. Assim, busca-se “[...] o desenvolvimento de um olhar poético sobre o mundo, olhar que nos descortina a poesia como um horizonte que se procura alcançar em construções artísticas como o poema, a canção, o quadro, a dança, etc.”. (DUARTE JR., 2010, p. 18).

A impossibilidade de separação da vida profissional da vida pessoal do professor é um tema que tem sido tratado atualmente por diversos pesquisadores na área educacional como Nóvoa (2003) e Tardif (2002), dentre outros. Desta forma, cabe pensar que as escolhas pedagógicas do professor para seu ensino tenham relação com a sua vida pessoal, visto que a inseparabilidade desses dois estados é fato estudado e verificado em inúmeras pesquisas no campo da Educação.

Assim, torna-se relevante pesquisar sobre a cultura visual no Ensino de Artes Visuais no tocante aos sentidos, práticas e experiências docentes, buscando nesses contextos, identificar a relação das vivências pessoais dos professores com as visualidades contemporâneas utilizadas em suas práticas. 


\section{Uma pesquisa em bases científicas - buscando compreensões}

Conforme apontado, foi realizado um levantamento bibliográfico em cinco bases de dados de publicações científicas: na SciELO, nos anais das reuniões científicas nacionais da ANPED e do Seminário Nacional de Pesquisa em Arte e Cultura Visual, e ainda nos artigos da Revista Visualidades (UFG) e no banco de teses e dissertações do Programa de Pósgraduação em Arte e Cultura Visual da Universidade Federal de Goiás (UFG). Utilizando as palavras-chave: Cultura Visual, Ensino de Artes Visuais e Formação de Professores, foi proposto o conhecimento sobre as produções científicas que tem convergência com o tema estudado nesta pesquisa. Possui caráter quali-quantitativo, buscando compreender a relevância e a quantidade de produções divulgadas, que possam auxiliar nas relações de estudo em campos diversos.

A seguir, apresentamos brevemente as bases de pesquisa utilizadas até o presente momento e os trabalhos em forma de artigos. Aqui descrevemos a busca realizada em apenas duas bases pesquisadas - na SciELO e na ANPED, pois é necessário dizer que esta pesquisa se encontra em estado inicial, e está apresentada de forma sucinta, e que não pretende esgotar a demanda por trabalhos que contribuam para o entendimento do tema. Isto se justifica, visto que todo olhar é sempre seletivo e compreende interpretações diversas, buscando apenas apresentar o que pode ser identificado como pertinente ao andamento da pesquisa.

SciELO é uma biblioteca eletrônica que apresenta uma seleção de periódicos científicos brasileiros, que conta com apoio do CNPq - Conselho Nacional de Desenvolvimento Científico e Tecnológico desde 2002. “O Projeto tem por objetivo o desenvolvimento de uma metodologia comum para a preparação, armazenamento, disseminação e avaliação da produção científica em formato eletrônico”. (SCIELO, 2017).

$\mathrm{Na}$ SciELO foi identificado um artigo de Sardelich (2006, p. 451) intitulado "Leitura de imagens, cultura visual e prática educativa”, que aponta a necessidade de uma alfabetização visual - leitura de imagens e compreensão crítica da cultura visual - e argumenta que "as frequentes mudanças de expressões e conceitos dificultam o entendimento dessas propostas para o currículo escolar, assim como a própria definição do professor ou professora que será responsável por esse conhecimento e seu referencial teórico". Assim, a autora apresenta conceitos que podem fundamentar as propostas em torno dos temas da cultura visual e da leitura de imagens, sugerindo possibilidades de trabalho para que se possa refletir sobre a formação docente. 
Além deste, foi selecionado o trabalho de Neitzel e Carvalho (2011), "Estética e arte na formação do professor da educação básica". Trata de investigar as concepções de professores dos anos finais do Ensino Fundamental de uma rede de ensino municipal do Brasil, em relação ao ensino de música, linguagem cênica, literatura e artes visuais, propiciado por estudos e vivências artísticas no curso de especialização em Docência na Educação Básica. O impacto dessas atividades foi verificado nas propostas na prática pedagógica do professor e concluiu-se que $60 \%$ dos professores perceberam mudanças no currículo, no repertório pessoal, principalmente por conta das vivências em artes visuais e das apresentações culturais. Ainda, 40\% demonstraram uma visão pedagógica das artes e $60 \%$ conceberam a arte como fruição.

A partir do estudo dos dois trabalhos - Sardelich (2006) e Neitzel e Carvalho (2011) - é possível perceber a necessidade da alfabetização visual e da constituição de um repertório pessoal, visando a formação estética de alunos e professores. Conforme sustenta Sardelich (2006), por se tratar de uma abordagem multireferencial e transdisciplinar,

[...] um trabalho de compreensão crítica da cultura visual nos mais variados ambientes de aprendizagem pode ser desenvolvido por qualquer educador/a que deseje e se disponha a problematizar as representações sociais de menina, menino, mulher, homem, família, criança, adolescente, adulto, [dentre outros]. O foco de um trabalho de compreensão crítica da cultura visual não está no que pensamos dessas representações, mas sim no que, a partir delas, possamos pensar sobre nós mesmos. O que falam de mim as representações de mulher, trabalhadora, professora, esposa, consumidora? O que não falam de mim? O que falam e não falam das pessoas iguais a mim e diferentes de mim? O que posso pensar de mim a partir dessas diferentes representações? Por que determinadas representações são sempre recorrentes? Que interesses são satisfeitos com essas representações? (SARDELICH, 2006, p. 468-469).

Vindo ao encontro das ideias apresentadas, Neitzel e Carvalho (2011, p. 118) percebem “[...] que as questões que envolvem a formação estética não constituem um processo simples, elas dependem de políticas institucionais e das relações desses profissionais nos contextos nos quais vivem, das suas iniciativas e interesses". Salientam ainda que a iniciativa pessoal é fator importante para a formação estética do sujeito, no entanto, para tanto é fundamental as concepções que o sujeito possa ter referentes à arte e à estética.

A ANPEd - Associação Nacional de Pós-Graduação e Pesquisa em Educação - é uma entidade sem fins lucrativos que une programas de pós-graduação stricto sensu em educação, professores e estudantes vinculados a estes programas e demais pesquisadores da área. "Ela tem por finalidade o desenvolvimento da ciência, da educação e da cultura, dentro dos 
princípios da participação democrática, da liberdade e da justiça social” (ANPED, 2017). Possui 23 Grupos de Trabalho (GTs) temáticos, que são instâncias de aglutinação e de socialização do conhecimento que congregam pesquisadores de áreas de conhecimento especializadas. Além de aprofundar o debate sobre interfaces da Educação por meio da apresentação de anais, definem atividades acadêmicas das Reuniões Científicas Nacionais da ANPEd. Tem o GT24, dedicado ao tema da Educação e Arte e o GT08, da Formação de Professores, que nos interessam no tocante a este estudo. É importante salientar que buscas em outros GTs são necessárias, pois alguns artigos se encontram pertinentes aos demais temas de interesse da Educação.

No portal da ANPEd foram selecionados três trabalhos pertencentes ao GT de Educação e Arte e ao GT de Educação e Comunicação. (LEITE, 2004; SOUZA, 2013; NOAL-GAI, 2015).

O artigo de Leite (2004, p. 01), "Livros de arte para crianças: um desafio na apropriação de imagens e ampliação de olhares” apresenta “[...] uma análise de livros de arte destinados a crianças, procurando iluminar de que maneira contribuem, ou não, com suas imagens e textos, para a ampliação de seus olhares e para que tenham experiências estéticas significativas". A autora entende o livro como um material cultural, e não um material para ensinar cultura, portanto acentua que a "didatização" dos livros de arte é um risco, visto que o primordial seria assegurar seu caráter artístico, e não apreendê-los por seu caráter pedagógicodidático-escolar. Acrescenta que "[...] a arte é, essencialmente, transgressora e livre; a escola, normatizadora". (LEITE, 2004, p. 14-15).

Souza (2013, p. 13) em "Cinema infantil, arte e indústria cultural” traz uma reflexão sobre o cinema infantil, sua produção e reprodução, identificando-o como uma mercadoria voltada para o público infantil, sustentado pela falsa justificativa de que, a criança, por ser "[...] incapaz de produzir cultura, deve ser bombardeada por "coisas boas" feitas e avaliadas por adultos competentes". O autor entende que a cultura deve ser realizada pelas crianças, "[...] em ambientes onde elas possam ser crianças, fazer história, construir histórias, [pois nos] processos formativos as crianças produzem cultura, exercendo sua condição de sujeito histórico". Ressalta ainda que o acesso aos bens artísticos é de suma importância, e que o caráter "didatizante" deveria ser posto de lado, pois a arte carrega por si só, seu potencial educacional.

O exercício de escrita de Noal-Gai (2015, p. 01), "Pedagogia de cartazes: artes, sensações, vulnerabilidade e aprendizagem" situa-se nos estudos de arte e memória numa 
perspectiva contemporânea, sustentado na "Pedagogia de cartazes"3 e no "entendimento da memória como duração, e justamente por isso, atualização". Entendendo os cartazes como visualidades e experiências visuais, se questiona sobre o que estes podem produzir, em termos de aprendizagem, naqueles em situação de vulnerabilidade: "Os estudantes com atenção, displicentemente, por acaso, por agenciamento, pelos inusitados dos dias, aproveitam-se do que os cartazes lhes mostram?”. Pretende investir em uma didática do compartilhamento, promotora de aprendizagem por sensações, considerando a diversidade e trazendo a criação para o centro do trabalho pedagógico.

Os textos de Leite (2002) e Souza (2013) debatem sobre o processo de apropriação cultural - na literatura e no cinema - compreendendo que este é complexo e constituído de múltiplas faces interpretativas. Assim como Leite (2002) sugere que "fazer circular a cultura é aspecto fundamental numa política de formação de adultos e crianças que, por sua complexidade, exige reflexão", Souza (2013) sustenta que a arte é objeto de reflexão pois

[...] não está apenas para a evidência do sensível, ao tornar o real visível, ao estranhar o mundo, a obra de arte cria objetivamente um outro mundo real, e neste mundo o particular representa o universal, e o universal expressa o particular, sem contudo dissolver a genericidade do particular e a especificidade do universal. (SOUZA, 2013, p. 01).

Ambos, Leite (2002) e Souza (2013) apontam que a aceleração da veiculação de imagens e mídias, com predomínio da informação sobre a narrativa (que teria possibilidade formativa) prejudica o aprofundamento na apreensão das visualidades. A informação excessiva “[...] impõe-nos tal invasão imagética que beira a banalização, enfraquecendo o olhar e favorecendo a cegueira. Olhar fugidio, que não penetra, não vê. É o olhar desviante, que enfraquece a compreensão". (LEITE, 2002, p. 05). Da mesma forma, as instituições escola e família, priorizam "[...] a relação das crianças com as coisas em detrimento das relações pessoais, naturalizando a criança, privilegia a objetividade destituída de subjetividade, e a subjetividade desassociada da objetividade, comprometendo a possibilidade da experiência estética”. (SOUZA, 2013, p. 01). Assim, a relação com a arte e a cultura (incluindo a visual) se dá de forma pragmática, ocasionando a fetichização dos bens artísticos/culturais e desconhecendo o valor do trabalho humano, na forma de uma anestesia dos sentidos. Como consequência, "[...] hipostasia a experiência, aliena a relação de

\footnotetext{
${ }^{3}$ Segundo Noal-Gai (2016, p. 479), a pedagogia de cartazes são "experimentos na pedagogia que envolvem a escrita, a pequena escrita, os enunciados breves, os alertas de perigos. Experimentos de escrita para além de uma pedagogia com cartolinas, crafts, folders, anúncios, panfletos, quadros mural, informativos de postes, bilhetes de portas - e ao mesmo tempo usurpando tudo que tenha efeito de captura e promoção de aprendizagem".
} 
alteridade, racionalizando toda a experiência estética, impede a experiência com a magia, com o imponderável”. (SOUZA, 2013, p. 01).

Por fim, Noal-Gai (2015) aposta na "Pedagogia de cartazes" como possibilidade de experiência visual na escola, questionando-se e a nós mesmos sobre as escrituras, como partilhas do sensível, que colocadas à mostra e em processo de comunhão com as coisas da comunidade, poderiam promover a experiência da aprendizagem. E assegura que:

Se pudéssemos falar das faculdades intuitivas sendo construídas por memórias arranjadas e conservadas com alegria, certamente afirmaríamos as experiências visuais, das artes ou triviais, como motor para tais combinações de ideias. Pensar em estratégias, reconhecer espaços, ter "sacadas inventivas", reconhecer a comunidade como espaço de encontros, de práticas, de vivências, de trocas e de aprendizagens. Inserir, como formas de experimentação dos campos de observação: vídeos, produção de imagens, fotos, cartografias -- para reconhecer territórios vivos. (2015, p. 09).

\section{Conclusões parciais}

Propomo-nos aqui, ressaltar alguns pontos que possibilitem conclusões, ainda que bastante incipientes. A busca pelas publicações científicas que entrelaçassem as temáticas da cultura visual e da formação docente em Artes Visuais é relevante para o nosso trabalho, na medida em que possibilita a reflexão sobre o tema. $\mathrm{O}$ conhecimento sobre as produções científicas da área e os entendimentos acerca da cultura visual no ensino e formação de professores, ainda que por vezes, não tão explícitos nos textos, ajudaram-nos a pensar sobre as possibilidades das relações entre os temas.

Entendendo que não existe um conceito único para a formação docente, mas que esta apresenta múltiplas perspectivas, é justificável pensar numa formação que é ofertada como possibilidade experiencial (que pode ser tomada por iniciativa pessoal do próprio sujeito), e outra que pode ser organizada como proposta formativa, realizada em grupos ou coordenada por outros sujeitos. Assim, embora os artigos científicos elencados não toquem diretamente na questão da formação do professor para o trabalho com a cultura visual, os textos trazem contribuições para se pensar sobre o tema. Na medida em que pensam a cultura como um aspecto fundamental numa política de formação de adultos e crianças, pensam também consequentemente - que estes adultos-professores necessitam de uma formação artística, que amplie seu repertório cultural, reverberando em suas práticas de sala de aula. 
Ainda, ao se referirem à cultura visual, refletem sobre a proliferação constante de imagens a que todos somos submetidos na contemporaneidade, onde ocorre o predomínio da informação sobre a experiência, causando um anestesiamento dos sentidos. Assim, é fundamental a compreensão da cultura visual quanto à multiplicidade de representações culturais, desmistificando juízos de valor estereotipados e produzindo um constante questionamento sobre o valor artístico das imagens levadas para a sala de aula, sejam livros, filmes, imagens publicitárias, fotografias e outras formas artísticas.

Portanto, os professores necessitam refletir sobre os artefatos visuais como produtos de um contexto histórico, cultural e social que afetam as concepções de arte e vida de seus alunos. Pensar em estratégias, reconhecendo espaços de intervenção, apostar em "sacadas inventivas", parece ser, segundo os autores estudados, fundamental para uma compreensão crítica da cultura visual, contemplando as vivências de estudantes e professores, dentro e fora da sala de aula.

Talvez pela fluidez das temáticas, e que estão constantemente serem retomadas e discutidas, não é possível uma conclusão única, visto que assumimos que a pesquisa encontrase em andamento e que sabemos, necessita ainda, e muito de mergulho e adensamento teórico. Porém, pelo levantamento realizado a partir das cinco bases, e que foram trabalhadas apenas duas neste artigo, já tem sido possível perceber a necessidade preemente de pesquisas na área, entrelaçando os temas da formação docente e cultura visual.

\section{REFERÊNCIAS}

ANDRADE, Paula Deporte de; COSTA, Marisa Vorraber. Usos e possibilidades do conceito de pedagogias culturais nas pesquisas em estudos culturais em educação. Textura. Canoas, v.17 n.34 p.48-63 mai./ago. 2015, p. 48-63. Disponível em:

http://www.periodicos.ulbra.br/index.php/txra/article/viewFile/1501/1140 Acesso em: 15 set. 2017.

ANPED (Associação Nacional de Pós-Graduação e Pesquisa em Educação). Disponível em: 〈http://www.anped.org.br/> Acesso em: 03 jun. 2017.

ASSMANN, Hugo. Reencantar a Educação. Rumo à sociedade aprendente. 8. ed. Petrópolis: Vozes, 2004.

DEBESSE, Maurice. La Formación de los Enseñantes. Barcelona: Oikos-Tau, 1982.

DUARTE JÚNIOR, João Francisco. A montanha e o videogame: Escritos sobre educação. Campinas: Papirus: 2010.

GARCÍA, Carlos Marcelo. Formação de Professores. Para uma mudança educativa. Porto: Porto, 1999. 
GIROUX, Henry; MCLAREN, Peter. Por uma pedagogia crítica da representação. In: SILVA, Tomaz T.; MOREIRA, Antônio F. (Org.). Territórios contestados: O currículo e os novos mapas políticos e culturais. Petrópolis: Vozes, 1998, p. 45-67.

GIROUX, Henry (1995). Praticando estudos culturais nas faculdades de educação. In: SILVA, Tomaz T. (Org.). Alienígenas na sala de aula: Uma introdução aos estudos culturais em educação. 3 ed. Petrópolis: Vozes, 1995, p. 131-159.

HERNÁNDEZ, Fernando. Cultura Visual - Mudança Educativa e projeto de trabalho. Porto Alegre: Artmed, 2000.

JOSSO, Marie-Christine. Experiências de Vida e Formação. São Paulo: Cortez, 2004.

LARROSA, Jorge. Literatura, experiência e formação. In: COSTA, Marisa Vorraber (org.). Caminhos Investigativos. Novos olhares na pesquisa em educação. 2. ed. Rio de Janeiro: DP\&A, 2002. p. 133-160.

LEITE, Maria Isabel. Livros de arte para crianças: um desafio na apropriação de imagens e ampliação de olhares. In: 27ª Reunião Anual da ANPED [Anais da...]. Caxambu, 2004. Disponível em: 〈http://www.anped.org.br/sites/default/files/t169.pdf> Acesso em: $10 \mathrm{abr}$. 2017.

MARTINS, Raimundo. Educação e poder: deslocamentos perceptivos e conceituais da cultura visual. In: OLIVEIRA, Marilda De Oliveira; HERNÁNDEZ, Fernando (Orgs.). A formação do professor e o Ensino das Artes Visuais. Santa Maria: editora UFSM, 2005.p.133-145.

MEIRA, Mirela R; SILVA, Ursula Rosa da. Cultura visual, Ensino da Arte e Cotidiano: Hibridismos e Paradoxos. Revista Visualidades. Goiânia, v 11, n² 2, p.37-57, 2013.

NEITZEL, Adair de Aguiar; CARVALHO, Carla. Estética e arte na formação do professor da educação básica. Rev. Lusófona de Educação, Lisboa, n. 17, p. 103-121, 2011. Disponível em: 〈http://www.scielo.mec.pt/scielo.php?script=sci_arttext\&pid=S1645-

$72502011000100008 \& \operatorname{lng}=$ pt\&nrm=iso $>$ Acesso em: 07 jul. 2017.

NELSON, Cary; TREICHLER, Paula A.; GROSSBERG, Lawrence. Estudos Culturais: Uma Introdução. In: SILVA, Tomaz Tadeu da (Org.). Alienígenas na Sala De Aula - Uma introdução aos estudos culturais em educação. 6 ed. Petrópolis: Vozes, 2005. p. 7- 34.

NOAL-GAI. Daniele. Pedagogia de cartazes: artes, sensações, vulnerabilidade e aprendizagem. In: 37 a Reunião Nacional da ANPEd [Anais da...] - 04 a 08 de outubro de 2015, UFSC - Florianópolis. Disponível em:

〈http://www.anped.org.br/sites/default/files/trabalho-gt24-3971.pdf > Acesso em: 10 abr. 2017.

NOAL-GAI. Daniele. Aprendizagem de sensações (ou por uma pedagogia de cartazes).

Quaestio, Sorocaba, SP, v. 18, n. 2 - edição especial, p. 477-488, set. 2016.

NÓVOA, António. Diz-me como ensinas, dir-te-ei quem és e vice-versa. In: FAZENDA, Ivani Catarina Arantes (org.). A pesquisa em educação e as transformações do conhecimento. 6.ed. Campinas: Papirus, 2004. p. 29-41. 
SARDELICH, Maria Emilia. Leitura de imagens, cultura visual e prática educativa. Cadernos de Pesquisa, v. 36, n. 128, p. 451-472, maio/ago. 2006. Disponível em: 〈http://www.scielo.br/pdf/cp/v36n128/v36n128a09> Acesso em: 03 jul. 2017.

SciELO (Scientific Electronic Library Online). Disponível em: 〈http://www.scielo.br/?lng=pt> Acesso em: 05 abr. 2017.

SOUZA, André Barcelos. Cinema infantil, arte e indústria cultural. In: $36^{\text {a }}$ Reunião Nacional da ANPEd [Anais da.... - 29 de setembro a 02 de outubro de 2013, Goiânia-GO. Disponível em: 〈http://www.anped.org.br/sites/default/files/gt24_2702_texto.pdf> Acesso em: 21 jul. 2017.

TARDIF, Maurice. Saberes docentes \& Formação profissional. Petrópolis: Vozes, 2002.

VIEIRA DA CUNHA, Susana Rangel. Pedagogias de imagens. In: DORNELLES, Leni Vieira. Produzindo pedagogias interculturais na infância. Rio de Janeiro: Vozes, 2007.

\section{SOBRE AS AUTORAS:}

\section{Maristani Polidori Zamperetti}

Doutora em Educação, Centro de Artes e Faculdade de Educação, Universidade Federal de Pelotas (UFPel). Líder do Grupo de Pesquisa: Pesquisa, Ensino e Formação Docente nas Artes Visuais (CNPq). E-mail: maristaniz@hotmail.com

\section{Fabiana Lopes de Souz}

Doutoranda em Educação pela Universidade Federal de Pelotas (UFPel). Colaboradora do Grupo de Pesquisa: Pesquisa, Ensino e Formação Docente nas Artes Visuais (CNPq). E-mail: fabiana.lopess2013@gmail.com 